\title{
Robust diagnosis of Ewing sarcoma by immunohistochemical detection of super-enhancer-driven EWSR1-ETS targets
}

\author{
Michaela C. Baldauf ${ }^{1, *}$, Martin F. Orth ${ }^{1, *}$, Marlene Dallmayer $^{1, *}$, Aruna Marchetto $^{1}$, \\ Julia S. Gerke ${ }^{1}$, Rebeca Alba Rubio ${ }^{1}$, Merve M. Kiran ${ }^{2}$, Julian Musa ${ }^{1}$, Maximilian \\ M. L. Knott ${ }^{1}$, Shunya Ohmura ${ }^{1}$, Jing Lí ${ }^{1}$, Nusret Akpolat ${ }^{3}$, Ayse N. Akatlí ${ }^{3}$, Özlem \\ Özen ${ }^{4}$, Uta Dirksen ${ }^{5}$, Wolfgang Hartmann ${ }^{6}$, Enrique de Alava7, Daniel Baumhoer ${ }^{8}$, \\ Giuseppina Sannino ${ }^{1}$, Thomas Kirchner ${ }^{9,10,11}$ and Thomas G. P. Grünewald ${ }^{1,9,10,11}$ \\ ${ }^{1}$ Max-Eder Research Group for Pediatric Sarcoma Biology, Institute of Pathology, Faculty of Medicine, LMU Munich, Munich, \\ Germany \\ 2 Department of Pathology, Medical Faculty, Ankara Yildirim Beyazit University, Ankara, Turkey \\ ${ }^{3}$ Department of Pathology, Turgut Ozal Medical Center, Inonu University, Malatya, Turkey \\ ${ }^{4}$ Department of Pathology, Başkent University Hospital, Ankara, Turkey \\ ${ }^{5}$ Department of Pediatric Hematology and Oncology, University Hospital Essen, Essen, Germany \\ ${ }^{6}$ Gerhard-Domagk-Institute for Pathology, University Hospital Münster, Westfalian Wilhelms University, Münster, Germany \\ ${ }^{7}$ Institute of Biomedicine of Seville (IBiS), Hospital Universitario Virgen del Rocío/CSIC/Universidad de Sevilla, CIBERONC, \\ Seville, Spain \\ ${ }^{8}$ Bone Tumour Reference Center, Institute of Pathology, University Hospital Basel, University of Basel, Basel, Switzerland \\ ${ }^{9}$ Institute of Pathology, Faculty of Medicine, LMU Munich, Munich, Germany \\ ${ }^{10}$ German Cancer Consortium (DKTK), Heidelberg, Germany \\ ${ }^{11}$ German Cancer Research Center (DKFZ), Heidelberg, Germany \\ * These authors have contributed equally to this work
}

Correspondence to: Thomas G.P. Grünewald, email: thomas.gruenewald@med.uni-muenchen.de Keywords: Ewing sarcoma, Ewing-like sarcoma, immunohistochemistry, BCL1 1B, GLG1

Received: July 18, $2017 \quad$ Accepted: July 23, $2017 \quad$ Published: August 04, 2017

Copyright: Baldauf et al. This is an open-access article distributed under the terms of the Creative Commons Attribution License 3.0 (CC BY 3.0), which permits unrestricted use, distribution, and reproduction in any medium, provided the original author and source are credited.

\section{ABSTRACT}

Ewing sarcoma is an undifferentiated small-round-cell sarcoma. Although molecular detection of pathognomonic EWSR1-ETS fusions such as EWSR1-FLI1 enables definitive diagnosis, substantial confusion can arise if molecular diagnostics are unavailable. Diagnosis based on the conventional immunohistochemical marker CD99 is unreliable due to its abundant expression in morphological mimics.

To identify novel diagnostic immunohistochemical markers for Ewing sarcoma, we performed comparative expression analyses in 768 tumors representing 21 entities including Ewing-like sarcomas, which confirmed that CIC-DUX4-, BCORCCNB3-, EWSR1-NFATC2-, and EWSR1-ETS-translocated sarcomas are distinct entities, and revealed that ATP1A1, BCL11B, and GLG1 constitute specific markers for Ewing sarcoma. Their high expression was validated by immunohistochemistry and proved to depend on EWSR1-FLI1-binding to highly active proximal super-enhancers. Automated cut-off-finding and combination-testing in a tissue-microarray comprising 174 samples demonstrated that detection of high BCL11B and/or GLG1 expression is sufficient to reach $\mathbf{9 6 \%}$ specificity for Ewing sarcoma. While $88 \%$ of tested Ewing-like sarcomas displayed strong CD99-immunoreactivity, none displayed combined strong BCL11B- and GLG1-immunoreactivity.

Collectively, we show that ATP1A1, BCL11B, and GLG1 are EWSR1-FLI1 targets, of which BCL11B and GLG1 offer a fast, simple, and cost-efficient way to diagnose 


\section{Ewing sarcoma by immunohistochemistry. These markers may significantly reduce the number of misdiagnosed patients, and thus improve patient care.}

\section{INTRODUCTION}

Ewing sarcoma is characterized by the presence of chimeric EWSR1-ETS fusion oncogenes [1]. Before the discovery of this unifying genetic hallmark, diagnosing Ewing sarcoma definitively was challenging [2] as Ewing sarcoma tumors are largely composed of undifferentiated cells displaying a small-round-cell phenotype [3,4]. This phenotype is shared by many other tumor entities such as rhabdomyosarcoma and neuroblastoma [5]. Recently, several so-called Ewing-like sarcoma subtypes have been identified [6-9]. These tumors are characterized by distinct fusion oncogenes and transcriptomic signatures [6-12], as well as (most likely) by distinct clinical behavior $[6,12$, 13].

Although Ewing sarcoma can usually be reliably distinguished from its morphological mimics by cytogenetic and molecular genetic analyses [14, 15], there is currently no robust biomarker available for routine histology. Substantial diagnostic confusion can arise because sophisticated cytogenetic and molecular diagnostic techniques are not universally available or too expensive for some diagnostic facilities (particularly in developing countries). While the widely used immunohistochemical biomarker CD99 shows high sensitivity for Ewing sarcoma, its low specificity and high expression in morphological mimics such as $C I C$ and $B C O R$-rearranged sarcomas, as well as in certain lymphoma subtypes and poorly differentiated synovial sarcoma, are problematic [3, 11-13, 16-18]. Thus, CD99 alone is unreliable to definitively diagnose Ewing sarcoma. Other studies identified auxiliary markers such as NKX2-2 and FLI1, which may help in some cases [19, 20]. However, a systematic and agnostic transcriptomewide screen for auxiliary markers and testing of their value when used in combination has not been done so far. In the current study, comparative expression analyses revealed that $A T P 1 A 1, B C L 11 B$, and GLG1 constitute potential specific markers for Ewing sarcoma. Expression of these genes appeared to be induced by EWSR1-FLI1bound super-enhancers, which showed high activity in reporter assays. Specific immunohistochemical staining of these proteins in comprehensive tissue microarrays (TMAs) combined with automated cut-off determination and combination-testing demonstrated that detecting high BCL11B and/or GLG1 levels is sufficient to reach $96 \%$ specificity for Ewing sarcoma. In fact, these markers were extremely effective at discriminating Ewing sarcoma from Ewing-like sarcomas.

Hence, these results provide a fast, simple, and cost-efficient means of diagnosing Ewing sarcoma by immunohistochemistry (IHC), which is a considerable advantage for diagnostic facilities where molecular diagnostics are not available. This finding may significantly reduce the number of misdiagnosed patients and thus improve patient care.

\section{RESULTS}

$A T P 1 A 1, B C L 11 B$, and $G L G 1$ are strongly overexpressed in Ewing sarcoma compared to tumor entities of differential diagnostic relevance

To identify highly specific diagnostic markers for Ewing sarcoma, we retrieved publicly available microarray gene expression data comprising genetically confirmed EWSR1-ETS-translocated Ewing sarcomas [21], 20 additional tumor entities of potential differential diagnostic relevance [5], and 71 normal tissue types. The set of morphological mimics also comprised CIC-DUX4-, BCOR-CCNB3-, and EWSR1-NFATC2-translocated sarcomas, which proved to be distinct entities as determined by unsupervised principal component analysis (PCA) (Supplementary Figure 1).

We then proceeded to perform comparative expression analysis on the entire dataset: Based on these microarray expression data the median expression of every gene represented on the Affymetrix HG-U133Plus2.0 microarray was determined. Next, we calculated the expression ratio (ER) for every gene based on its median expression in pairwise comparisons of Ewing sarcoma and the remaining tumor entities. Only genes, which were strongly overexpressed in Ewing sarcoma compared to all other tumor entities defined by a minimal log2-transformed ER of $>2$, were considered as diagnostically relevant. Of the 19,702 genes represented on the microarray platform, 51 had an ER of $>2$ across all tested tumor entities. In parallel, the level of significance of the differential expression of all genes in pairwise comparisons of Ewing sarcoma relative to all other tumor entities was calculated. Only 10 genes exhibited a Bonferroni-corrected $P$ value $<$ 0.05 (Figure 1A, 1B). Next, both gene lists were crossed, which showed that only 3 genes, termed ATP1Al (ATPase $\mathrm{Na}^{+} / \mathrm{K}^{+}$transporting subunit alpha1), BCL11B (B-cell CLL/lymphoma 11B), and GLG1 (Golgi glycoprotein 1) were both strongly and highly significantly overexpressed in Ewing sarcoma compared to all other tumor entities (Figure 1B).

Then, the expression profiles of these three candidate biomarkers were compared to the conventional 
Table 1: Composition of the TMA

\begin{tabular}{|l|c|}
\hline Entity & $\boldsymbol{n}$ \\
\hline Ewing sarcoma & 47 \\
\hline Alveolar Soft Part Sarcoma & 3 \\
\hline Ewing-like sarcoma & 17 \\
\hline Ganglioneuroblastoma & 7 \\
\hline Leiomyosarcoma & 5 \\
\hline Liposarcoma & 19 \\
\hline Malignant Fibrous Histiocytoma & 3 \\
\hline Nephroblastoma & 21 \\
\hline Neuroblastoma & 16 \\
\hline Osteosarcoma & 15 \\
\hline Rhabdomyosarcoma & 11 \\
\hline Synovial sarcoma & 10 \\
\hline $\boldsymbol{n}$ total: & $\mathbf{1 7 4}$ \\
\hline
\end{tabular}

Ewing sarcoma marker $C D 99$ across all tumor entities. While $C D 99$ showed broad expression in many different tumor entities, $A T P 1 A 1, B C L 11 B$, and GLG1 were only expressed at low levels in every tumor entity relative to Ewing sarcoma, indicating a higher specificity for this disease than $C D 99$ (Figure 1C).

Because commixture of tumor tissue with normal cells, which could express the three markers, could complicate immunohistochemical evaluation, we explored the expression levels of $A T P 1 A 1, B C L 11 B$, and $G L G 1$ and that of $C D 99$ in Ewing sarcoma samples relative to 71 normal tissue types comprising 998 samples. As displayed in Supplementary Figure 2, ATP1A1, BCL11B, and GLG1 were only lowly expressed in some normal tissue types, while $C D 99$ was rather broadly expressed across many normal tissue types. In fact, our three markers, except for $B C L 11 B$ in thymus, were statistically significantly higher $(P<0.05)$ expressed in Ewing sarcoma as compared to any tested normal tissue type.

\section{EWSR1-FLI1 induces ATP1A1, BCL11B, and GLG1 expression by binding to GGAA- microsatellites found in super-enhancers}

The specific expression of the three candidate biomarkers in primary Ewing sarcoma suggests a possible regulatory relationship between them and EWSR1-FLI1. In fact, ATP1A1 and GLG1 were previously shown to be upregulated after ectopic expression of EWSR1-FLII in the rhabdomyosarcoma cell line RD [22]. Moreover, $B C L 11 B$ was shown to be upregulated by EWSR1-FLI1 in Ewing sarcoma cell lines [23].

To further explore this regulatory relationship, available gene expression data were assessed, which showed that the ectopic EWSR1-FLI1 expression in embryonic stem cells was sufficient to significantly induce the expression of ATP1A1, BCL11B, and GLG1 (Figure 2A). Conversely, the shRNA-mediated knockdown of EWSR1-FLI1 in six different Ewing sarcoma cell lines significantly decreased their expression levels (Figure 2B). Such consistent EWSR1-FLI1-dependent regulation was not observed for $C D 99$ (Figure 2A, 2B).

These data in cell lines suggested that ATP1A1, $B C L 11 B$, and $G L G 1$ may be direct EWSR1-FLI1 target genes. Testing this hypothesis involved analyzing available ChIP-Seq and DNase-Seq data generated in Ewing sarcoma cell lines, which showed strong EWSR1-FLI1-binding to GGAA-microsatellites close to these genes. Notably, these GGAA-microsatellites exhibit characteristics of active EWSR1-FLI1-dependent enhancers (Figure 3A). In fact, EWSR1-FLI1 is known to convert non-functional GGAA-microsatellites into potent enhancers to steer a large proportion of its target genes [2426]. Strong EWSR1-FLI1-dependent enhancer activity of these GGAA-microsatellites in luciferase reporter assays was consistently observed (Figure 3B). In agreement with previous observations [27], these EWSR1-FLI1dependent enhancers showed the typical H3K27ac profile of so-called super-enhancers in the A673 and SK-N-MC Ewing sarcoma cell lines (Figure 3C, Supplementary Tables $1 \& 2$ ). Super-enhancers are often found near genes that have cell type-specific functions and contribute to cell identity $[28,29]$. In addition to these findings in vitro, gene-set enrichment analyses of either ATP1A1-, $B C L 11 B-$, or $G L G 1$-correlated genes within 166 primary Ewing sarcoma tumors revealed that the most significantly $(\min . \mathrm{NES}=3.08, P<0.001, \mathrm{q}<0.001)$ associated gene expression signature among the 3,687 tested was for each candidate marker 'ZHANG_TARGETS_OF_EWSR1FLI1 FUSION' [22] (Supplementary Table 3). Consistent with the previous finding that EWSR1-FLI1 and EWSR1- 
A
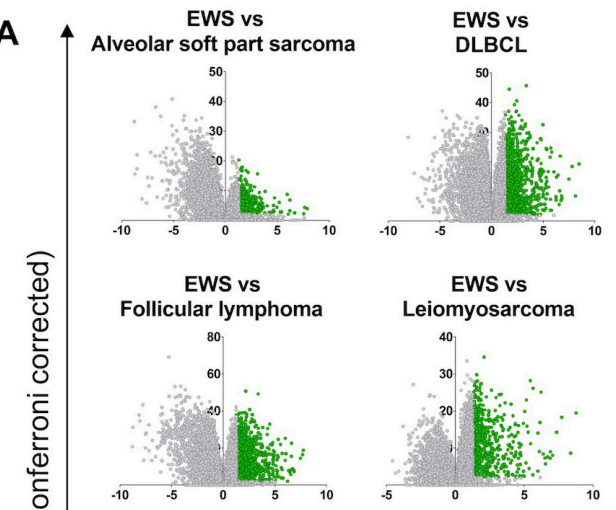

EWS vs

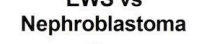

MPNST

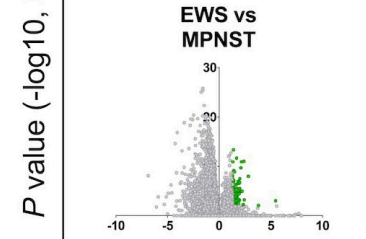

EWS vs
ARMS fusion-negative

ARMS fusion
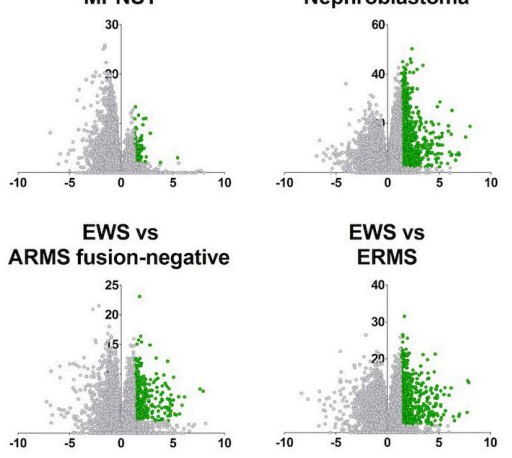
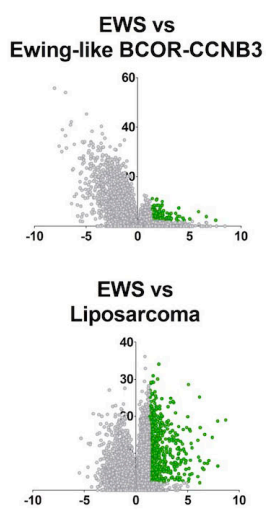

EWS vs

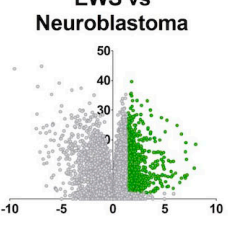

EWS vs

Retinoblastoma

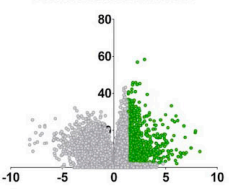

EWS vs

Ewing-like CIC-DUX4

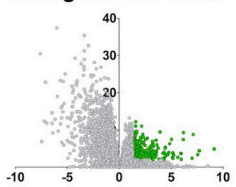

EWS vs

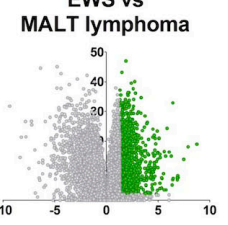

EWS vs

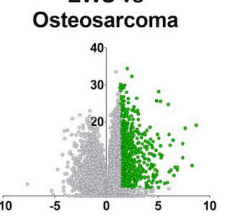

EWS vs

Synovial sarcoma

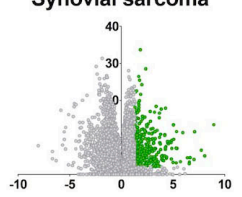

EWS vs

EWSR1-NFATc2 sarcoma
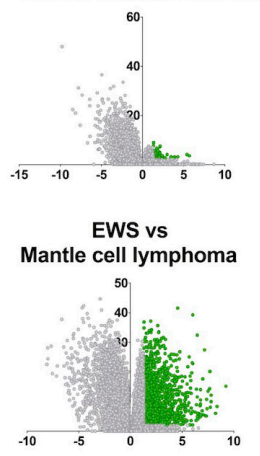

EWS vs

ARMS fusion-positive

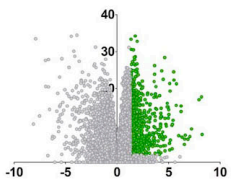

EWS vs

Undifferentiated sarcoma

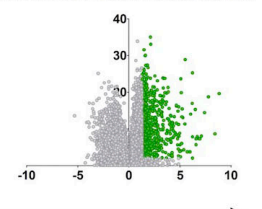

Expression ratio ( $\log 2)$

B

Genes with an expression ratio $(\log 2)>2$ in all comparisons as in Fig. 1a

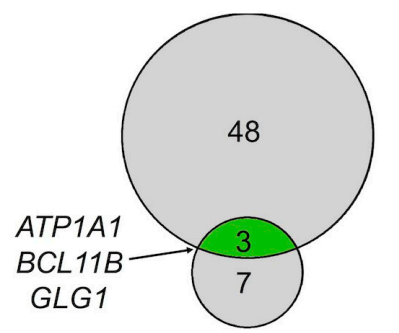

Genes with a

$P$ value $<0.05$ in all comparisons as in Fig. 1a
C

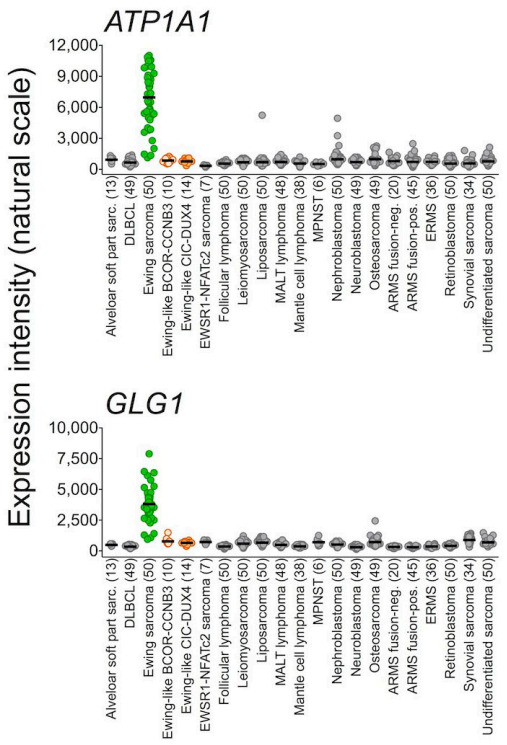

$B C L 11 B$

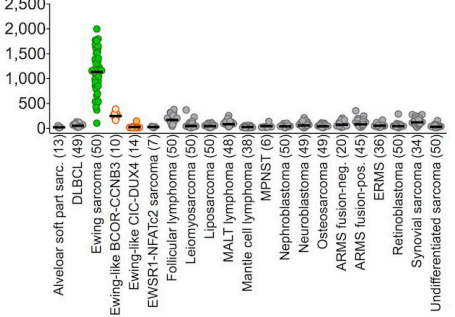

CD99

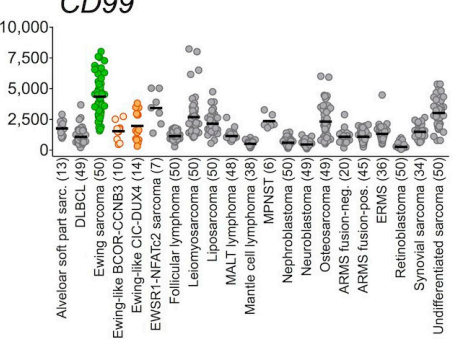

Figure 1: $A T P 1 A 1, B C L 11 B$, and $G L G 1$ are strongly overexpressed in Ewing sarcoma compared to tumor entities of differential diagnostic relevance. A. Volcano plots of pairwise comparison of gene expression in Ewing sarcoma (EWS) and indicated tumor entities. Diffuse large B-cell lymphoma (DLBCL); mucosa-associated lymphoid tissue (MALT) lymphoma; malignant peripheral nerve sheath tumor (MPNST); alveolar rhabdomyosarcoma (ARMS); and embryonal rhabdomyosarcoma (ERMS). Genes represented in green color had an expression ratio $>2(\log 2)$ and a $P$ value $<0.05$ (Bonferroni-corrected). B. Size-proportional Venn diagram showing the overlap of genes highly and significantly (minimal $\log 2$ expression ratio $>2 ; P$ value $<0.05$, Bonferroni corrected) overexpressed in Ewing sarcoma relative to all other tumor entities given in A and C. C. Scatter dot plot depicting gene expression levels of ATP1A1, BCL11B, GLG1, and CD99 as determined by Affymetrix HG-U133Plus2.0 microarrays in primary tumors of 21 different entities. Ewing sarcoma is highlighted in green, Ewing-like sarcomas (CIC-DUX4 or BCOR-CCNB3 translocation positive) are highlighted in orange. Horizontal bars represent median expression levels. The number of analyzed samples is given in parentheses. 
ERG bind to highly similar DNA-motifs [30], all three genes are similarly highly expressed in Ewing sarcoma cell lines regardless of the specific EWSR1-ETS status (Supplementary Figure 3). Collectively, these data strongly suggest that $A T P 1 A 1, B C L 11 B$, and $G L G 1$ are direct EWSR1-ETS target genes.
$A T P 1 A 1$ and $G L G 1$ may have prognostic relevance in Ewing sarcoma

To explore the potential of ATP1A1, BCL11B, $G L G 1$, and $C D 99$ as prognostic biomarkers, we analyzed the association of their expression levels with outcome in a

\section{A}

Embryonic stem cells

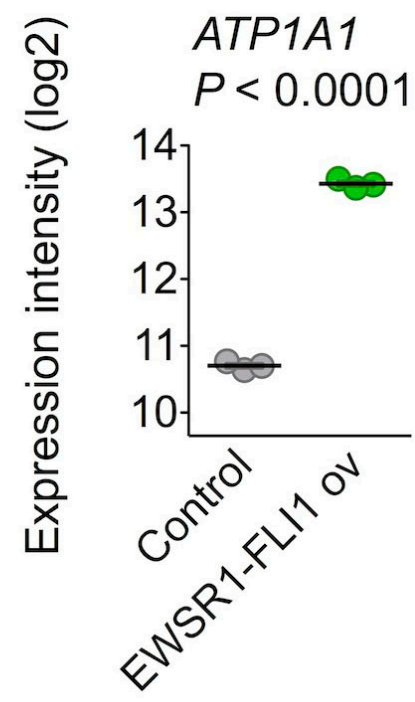

$B C L 11 B$

$P<0.0001$

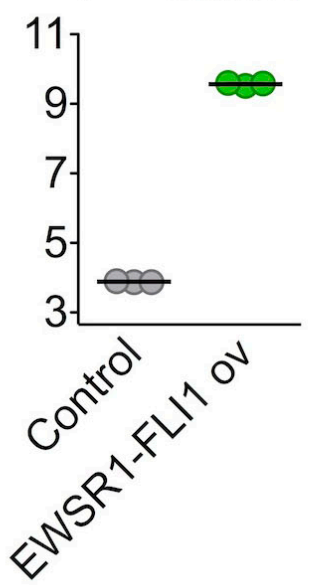

GLG1

$P=0.0008$

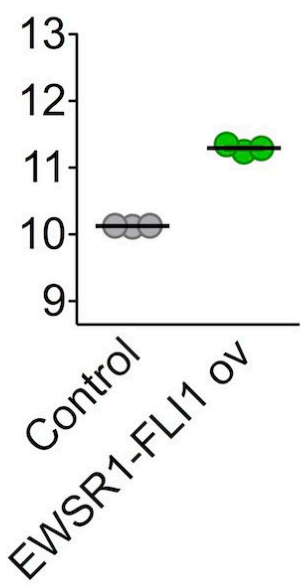

CD99

$P=0.0027$

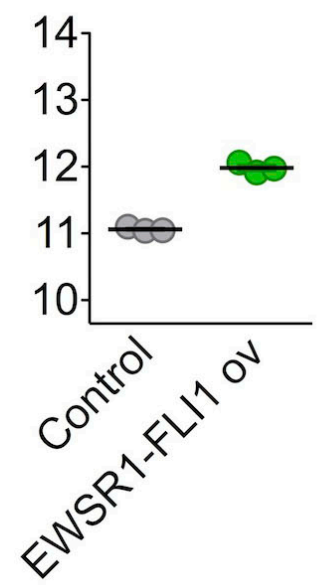

B

Ewing sarcoma cell lines

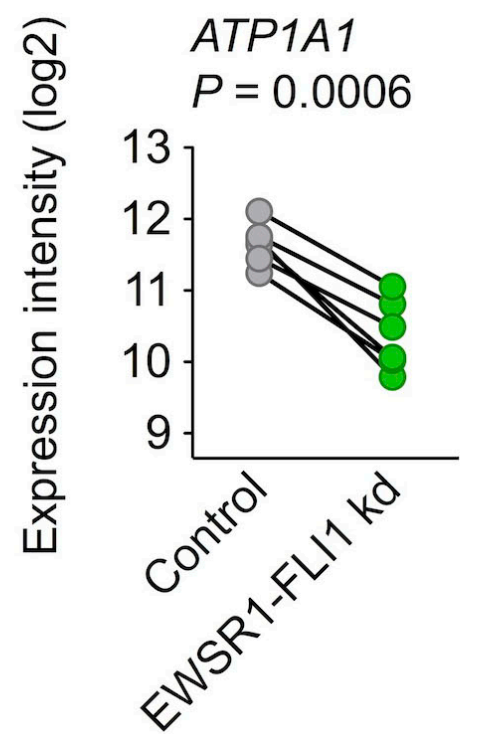

$B C L 11 B$

$P=0.0008$

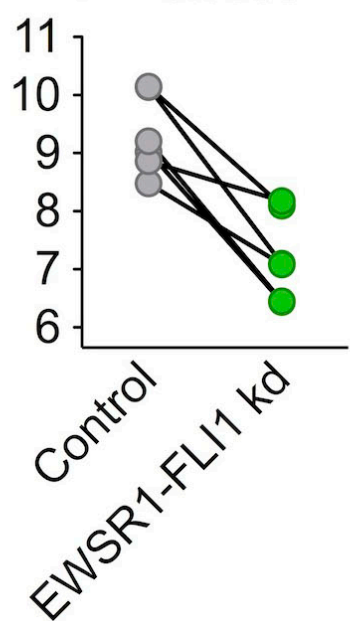

GLG1

$P=0.0135$

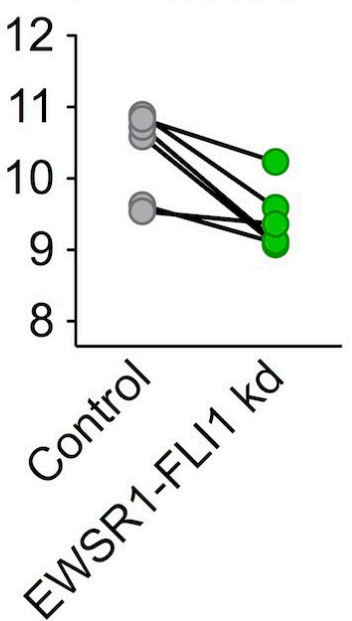

CD99

$P=0.148$

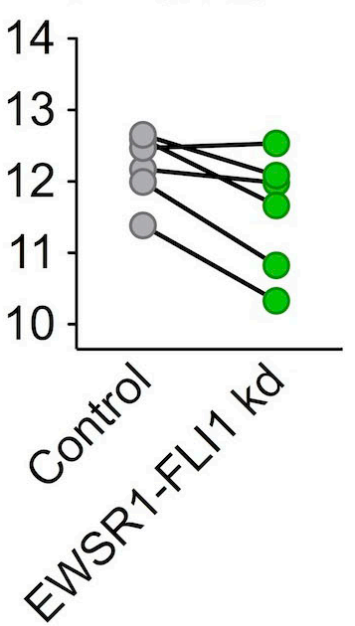

Figure 2: EWSR1-FLI1 is sufficient to induce $A T P 1 A 1, B C L 11 B$, and $G L G 1$ expression. A. Analysis of gene expression levels of $A T P 1 A 1, B C L 11 B, G L G 1$, and $C D 99$ by Affymetrix HG-U133Plus 2.0 microarrays in human embryonic stem cells after ectopic expression of EWSR1-FLI1 (GSE64686). Bars represent the medians. Two-tailed student's $t$ test. B. Analysis of gene expression levels of $A T P 1 A 1, B C L 11 B, G L G 1$, and CD99 by Affymetrix HG-U133A microarrays $96 \mathrm{~h}$ after short hairpin RNA-mediated knockdown (kd) of EWSR1-FLI1 in six different Ewing sarcoma cell lines (GSE14543 and GSE27524). Data are represented as before-after plots in which each dot represents a cell line. Two-tailed student's $t$ test. 
large cohort of Ewing sarcoma patients $(n=166)$. Whereas higher ATP1A1 and GLG1 expression levels showed a significant correlation with better patient outcome $(P=$ 0.006 and $P=0.0028$, respectively), BCL11B and $C D 99$

A

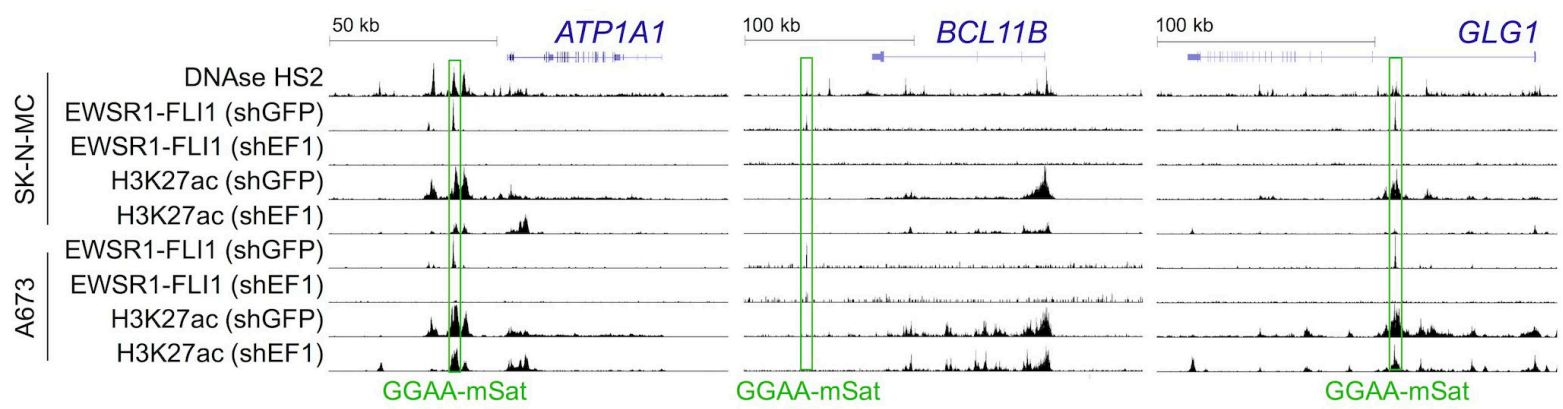

B

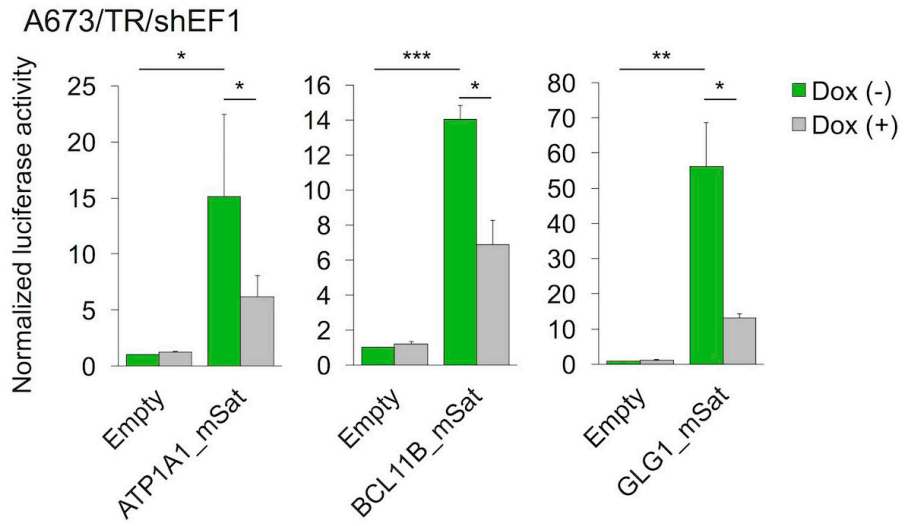

A673/TR/shEF1

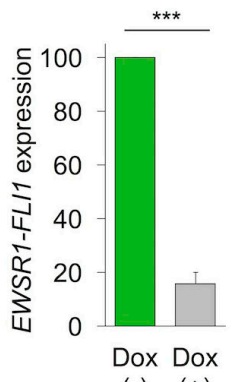

$(-) \quad(+)$

C
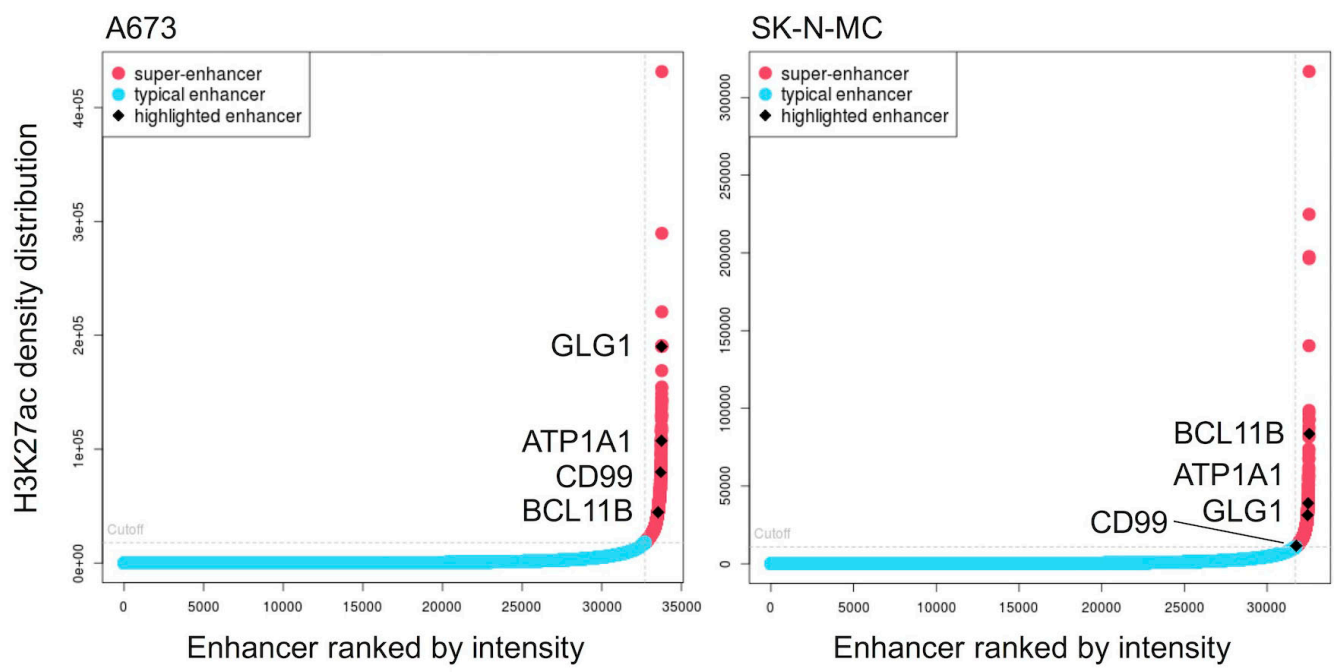

Figure 3: EWSR1-FLI1 binds to GGAA-microsatellites with enhancer activity located close to or within the $A T P 1 A 1$, BCLI1B, or GLG1 gene. A. Published DNase-Seq and ChIP-Seq data generated in Ewing sarcoma cell lines were displayed in the UCSC genome browser. shGFP, control; shEF1, shEWSR1-FLI1; GGAA-mSat, GGAA-microsatellite. B. Luciferase reporter assays in A673/TR/shEF1 cells containing a doxycycline (Dox)-inducible shRNA against EWSR1-FLI1 confirmed the EWSR1-FLI1-dependent enhancer activity of cloned GGAA-microsatellites (1 kb fragments). EWSR1-FLI1 knockdown was confirmed by qRT-PCR $72 \mathrm{~h}$ after shRNA induction. Data are presented as mean and SEM of $n=3$ independent experiments. Two-tailed student's $t$-test. * $P<0.05$; $* *$ $P<0.01$; *** $P<0.001$. C. Genome-wide analysis of published H3K27ac profiles of A673 and SK-N-MC Ewing sarcoma cell lines (GSE61944) identified super-enhancers proximal to ATP1A1, BCL11B, GLG1, and CD99. Enhancers are ranked by their H3K27ac density. 
expression levels did not (Supplementary Figure 4).

\section{High expression of BCL11B and/or GLG1 is sufficient to robustly diagnose Ewing sarcoma by IHC}

To confirm the overexpression of ATP1A1, BCL11B, and GLG1 on the protein level, a comprehensive TMA including many solid tumor entities closely resembling Ewing sarcoma and other sarcoma entities was generated (Table 1). Immunohistochemical staining of the TMAs was carried out with anti-ATP1A1, anti-BCL11B, antiGLG1, and anti-CD99 antibodies, and immunoreactivity scores (IRS) were determined in analogy to the Remmele and Stegner [31] scoring system (IRS range from 0 to 12; Figure 4A, 4b). As displayed in Figure 4B, CD99 expression was not very specific for Ewing sarcoma
A
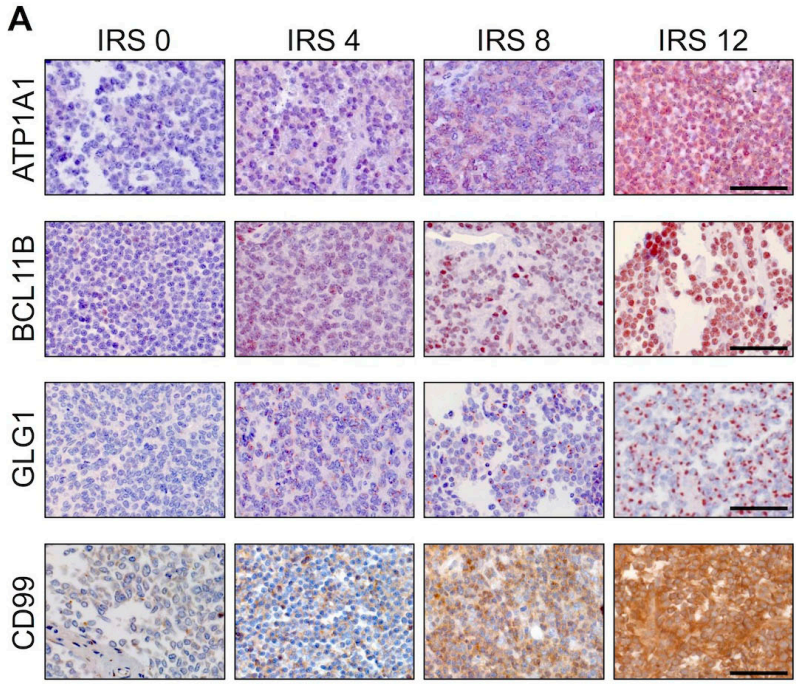

C

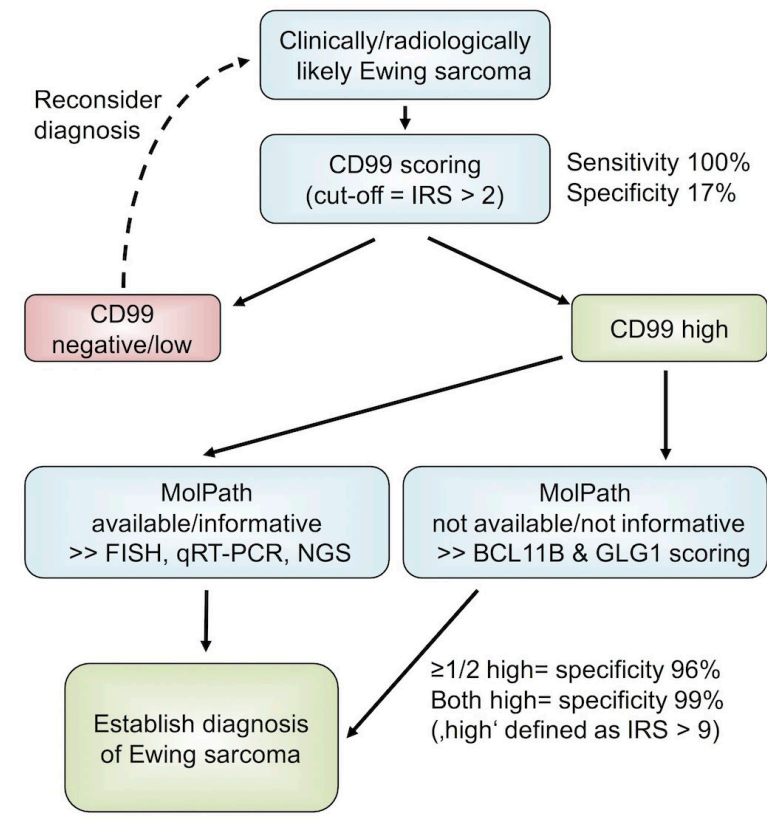

B
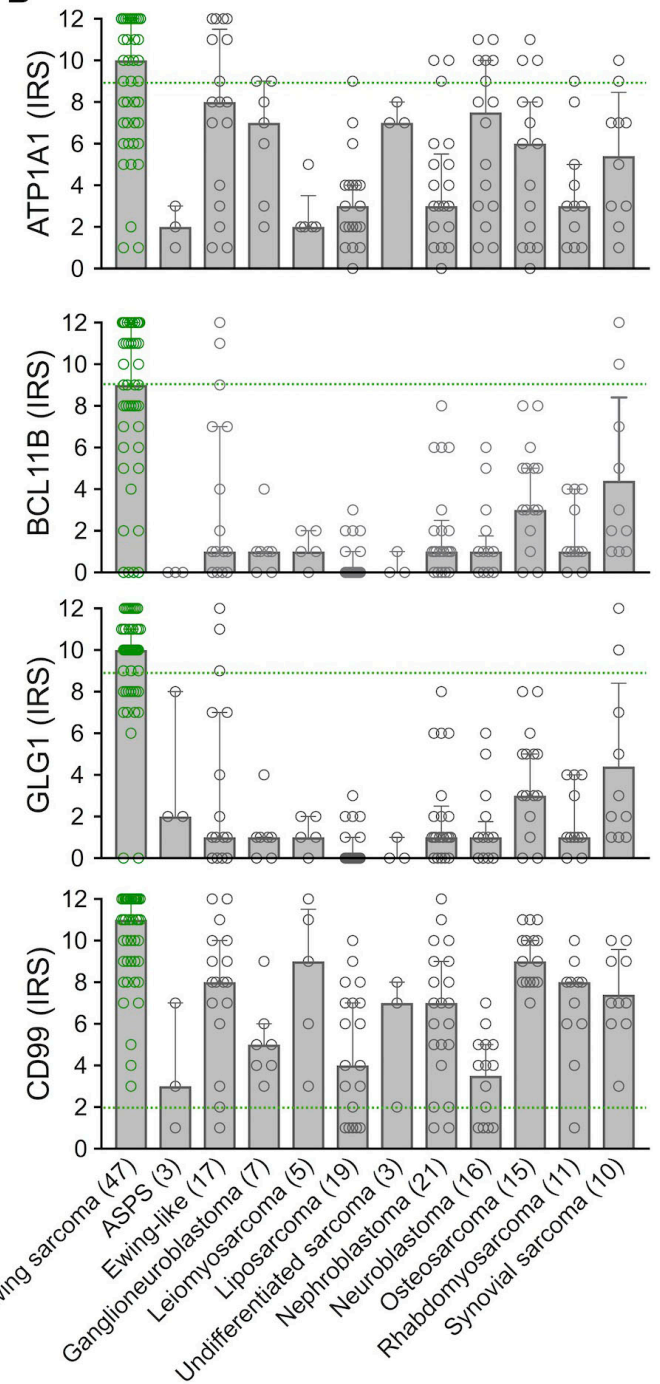

$\begin{array}{rccc}\text { Marker } & \text { Cut-off } & \text { Sensitivity (\%) } & \text { Specificity (\%) } \\ \text { ATP1A1 } & >9 & 51 & 90 \\ \text { BCL11B } & >9 & 45 & 97 \\ \text { GLG1 } & >9 & 64 & 96 \\ \text { CD99 } & >2 & 100 & 17\end{array}$

Figure 4: High expression of BCL11B and/or GLG1 is sufficient to robustly diagnose Ewing sarcoma by IHC. A. Representative IHC images for the indicated marker. ATP1A1 is expressed in the cytoplasm, BCL11B in the nucleus, GLG1 at the perinuclear Golgi apparatus, and CD99 at the membrane. Scale bars $=100 \mu \mathrm{m}$. For ATP1A1, BCL11B, and GLG1 a red and for CD99 a brown chromogen was used. B. Scatter dot plots of the individual IRS for the indicated marker. The number of analyzed samples is given in parentheses. Bars represent mean IRS values, whiskers indicate the 95\%-CI. Green dashed lines indicate the cut-offs to define sensitivity and specificity for detecting Ewing sarcoma as given in the table below. ASPS: alveolar soft part sarcoma. Ewing samples are highlighted in green color. C. Proposed work-flow for establishing robust diagnosis of Ewing sarcoma. 
compared to other sarcoma entities as well as Ewing-like sarcomas. However, CD99 reached 100\% sensitivity for Ewing sarcoma in this TMA when applying a cut-off of IRS $>2$. Compared to CD99, the three candidate markers were all less sensitive at any given cut-off, but much more specific (specificity 90 - 97\%) when being highly expressed (defined as IRS > 9) (Supplementary Table 4).

Automated cut-off-finding and combination-testing algorithms were then applied to the samples and set of candidate markers to identify a minimal set of markers and optimal cut-offs for robustly diagnosing Ewing sarcoma by IHC. These analyses indicated that while CD99 is a very valuable marker for screening for Ewing sarcoma, it needs auxiliary markers to establish a robust diagnosis. Further analyses indicated that while ATP1A1 exhibited high specificity (90\%), it had no additional value for establishing Ewing sarcoma diagnosis if it was combined with BCL11B and GLG1. In fact, detecting high BCL11B and/or GLG1 expression in CD99-high tumors reached a specificity for Ewing sarcoma of at least $96 \%$, and of $99 \%$ if both markers were highly expressed (defined as IRS $>9$ ). Strikingly, strong combined immunoreactivity for BCL11B and GLG1 was not observed in any of the tested Ewing-like sarcomas, while CD99 immunoreactivity was found in 15 of 17 cases $(88 \%)$.

Thus, the following work-flow is proposed to establish a diagnosis of Ewing sarcoma (Figure 4C): In the case of clinically and/or radiologically suspected Ewing sarcoma, a biopsy should first be stained for CD99. If CD99 is positive (defined as IRS $>2$ ), confirmatory molecular diagnostic procedures (such as FISH, qRTPCR, and/or next-generation sequencing), if available, are preferred. If molecular diagnostic procedures are unavailable or the biopsy material is not suitable, an IHCstaining for BCL11B and GLG1 as well as subsequent scoring according to the Remmele and Stegner system should be performed. Since high expression of BCL11B and/or GLG1 (defined as IRS > 9) was found in 79\% of all Ewing Sarcoma cases and associated with a specificity of $96 \%$, diagnosis of Ewing sarcoma should be strongly considered if one or both markers are highly expressed.

Collectively, our data provide evidence that fast and robust diagnosis of Ewing sarcoma is enabled by immunohistochemical detection of the super-enhancerdriven EWSR1-ETS targets BCL11B and GLG1.

\section{DISCUSSION}

Ewing sarcoma is genetically defined by pathognomonic EWSR1-ETS fusion transcripts [1]. To date, at least 18 types of chimeric EWSR1-FLI1 transcripts have been reported [6]. Alternatively, $E W S R 1$ can be fused with $E R G, E T V 1, E 1 A-F$ (alias ETV4) or FEV in Ewing sarcoma [6]. Although CIC-DUX4- and BCOR-CCNB3translocated sarcomas were shown previously to be distinct from EWSR1-ETS-translocated Ewing sarcomas
$[12,32]$, the situation was less clear for EWSR1-NFATc2translocated sarcomas. In fact, these tumors were until recently still considered by some authors as being simply a variant of Ewing sarcoma [33]. However, our PCA showed that EWSR1-NFATC2-translocated sarcomas are clearly distinct from EWSR1-ETS-translocated Ewing sarcomas, and confirm that EWSR1-NFATC2-translocated sarcomas also do not show any transcriptomic similarity with neither $C I C$-DUX4- nor BCOR-CCNB3-translocated sarcomas (Supplementary Figure 1).

Although several molecular diagnostic tools are available to identify Ewing sarcoma among morphological mimics by detecting these gene fusions (e.g. by FISH, qRT-PCR, and/or direct sequencing), there are several limitations: All these techniques require good-quality DNA or RNA, which is not available in more than $10 \%$ of cases [11]. In addition, FISH can sometimes yield non-informative results [14]. Moreover, there is a risk of falsely diagnosing a tumor as Ewing sarcoma based on FISH, because break-apart of the EWSR 1 gene can also be observed in other sarcoma entities such as desmoplastic small-round-cell tumor (DSRCT), clear cell sarcoma, angiomatoid fibrous histiocytoma, extraskeletal myxoid chondrosarcoma, and a subset of myxoid liposarcoma [34]. Conversely, PCR-based assays can yield false negative results as the PCR may not cover the entire spectrum of different EWSR1-ETS fusions. Thus, some authors recommend combining FISH and qRT-PCR [11]. However, these sophisticated techniques are not available in all diagnostic facilities, especially in developing countries, which poses a significant obstacle to accurately diagnosing Ewing sarcoma.

To offer a simple, fast, and cost-effective way to reliably diagnose Ewing sarcoma by IHC, we combined in silico, in vitro, and in situ analyses, and found that the high expression of BCL11B and/or GLG1 is nearly diagnostic for this disease. It was shown that both genes are direct EWSR1-FLI1-targets, which are specifically overexpressed in Ewing sarcoma. In fact, their genetic loci exhibit EWSR1-FLI1-dependent super-enhancers that usually control the expression of tissue-defining genes [28]. In particular, the high expression of the chosen markers was highly effective in discriminating Ewing sarcoma from EWSR1-ETS-negative Ewing-like sarcomas, which expressed CD99 at high levels in $88 \%$ of our cases. Nevertheless, it should be noted that some small-round-cell sarcoma subtypes such as DSRCTs could not be included in our primary screen as compatible gene expression microarrays were not publicly available. However, Surdez et al. published a transcriptomic comparison of DSRCTs and the same Ewing sarcoma samples as used in the current study, which proved that none of our markers ranges among the top 150 overexpressed probesets in DSRCT [35]. This finding was replicated in a subsequent study [25].

Previously, another EWSR1-FLI1 target gene, 
NKX2-2, was proposed to serve in combination with CD99 as a useful immunohistochemical marker for Ewing sarcoma [36]. In our comparative microarray analyses, NKX2-2 did not, however, meet the stringent selection criteria for further validation. Similarly, another report showed that NKX2-2 is not fully specific for Ewing sarcoma [20].

Although most Ewing sarcoma tumors show only little infiltration by lymphocytes [37], the fact that $B C L 11 B$ is expressed in normal T cells (Supplementary Figure 2) should be taken into account when assessing immunoreactivity in small-round-cell tumors. In indeterminate cases, a CD3 staining may be helpful (Supplementary Figure 5).

In agreement with similar findings on different markers in other cancer entities [38, 39], ATP1A1 and $G L G 1$ may have diagnostic as well as prognostic utility. However, this finding needs to be validated in an independent and larger cohort on the protein level.

Interestingly, all three original candidate markers play a role in fibroblast growth factor (FGF)-signaling. ATP1A1 is required for unconventional secretion of FGF [40], BCL11B promotes FGF-signaling by transcriptional suppression of a negative feedback inhibitor [23, 41], and GLG1 (alias cysteine-rich FGF receptor) is known to regulate intracellular levels of FGF [42]. Several studies have shown that FGF promotes EWSR1-FLI1 expression [43] and growth of Ewing sarcoma cells in vitro and in vivo $[25,41]$, and that FGF-inhibitors could be used as a targeted treatment for Ewing sarcoma patients [44]. Although more work needs to be done to elucidate the precise role of ATP1A1, BCL11B, and GLG1 in FGFsignaling, it is tempting to speculate that they could serve as predictive biomarkers for the efficacy of FGFinhibitors.

Collectively, we propose utilizing BCL11B and GLG1 as novel biomarkers for the diagnosis of Ewing sarcoma and recommend validating their diagnostic value in a prospective and multi-centered setting. It will be essential to further develop and characterize specific monoclonal antibodies directed against these proteins to improve and standardize their diagnostic utility.

\section{MATERIALS AND METHODS}

\section{Human samples and ethics approval}

Human tissue samples were retrieved from the archives of the Institute of Pathology of the LMU Munich (Germany), the Department of Pathology, Turgut Ozal Medical Center, Inonu University (Turkey), the Başkent University Hospital (Turkey), the Gerhard-DomagkInstitute for Pathology of the University of Münster (Germany), the Institute of Biomedicine of Seville (Spain), and the Bone Tumour Reference Centre at the Institute of Pathology of the University Hospital Basel (Switzerland) with approval of the corresponding institutional review boards. The LMU Munich's ethics committee approved the current study (approval no. 550-16 UE).

\section{Microarray analyses}

Publicly available gene expression data generated with the Affymetrix HG-U133Plus2.0 DNA microarray for 1,790 samples comprising 21 tumor entities and 71 normal tissue types were retrieved from several repositories. Accession codes are given in Supplementary Table 5. All Ewing sarcoma samples were genetically verified to contain a specific EWSR1-ETS translocation as previously described [21]. After rigorous quality-checks (including the Relative Log Expression (RLE) and Normalized Unscaled Standard Error (NUSE)) and careful clinical annotation validation, expression intensities were calculated simultaneously with the Robust Multi-array Average (RMA) algorithm (including background adjustment, quantile normalization, and summarization), using custom brainarray chip description file (CDF, ENTREZG, V19), which yielded one optimized probe-set per gene [45]. The pairwise ER of every gene was calculated based on its median expression levels in primary Ewing sarcoma tumors and any of the 20 other remaining tumor entities. The differential gene expression's statistical significance was calculated with an unpaired, two-tailed Student's $t$-test. The resulting $P$ values were adjusted for multiple testing with the Bonferroni method. Only genes with an ER of $>2$ between Ewing sarcoma and any other tumor entity and a Bonferroni-corrected $P$ value $<0.05$ across all tumor entities compared with Ewing sarcoma were considered diagnostically relevant. PCA was performed in $\mathrm{R}$ [46]. Publicly available gene expression microarray data for ectopic EWSR1-FLI1 expression in embryonic stem cells (Affymetrix HG-U133Plus2.0; GSE64686 [47]) and from Ewing sarcoma cell lines that were either transiently transfected with an shRNA directed against EWSR1-FLI1 or a control shRNA (TC252, SK-N-MC, STA-ET-7.2, STA-ET-1, WE68; Affymetrix HG-U133A; GSE14543 [48]) or stably transduced with a doxycycline-inducible shRNA against EWSR1-FLI1 (A673; Affymetrix HGU133A 2.0; GSE27524 [49]) were normalized by RMA using custom brainarray CDF (ENTREZG, v19).

To identify the pathways and biological processes associated with a given gene present in normalized gene expression data from primary Ewing sarcoma tumors, gene-set enrichment analyses (GSEAs) were performed on ranked lists of genes in which all genes were ranked by their correlation coefficient with the given reference gene (MSigDB, c2.all.v5.1). GSEA was carried out with 1,000 permutations in default settings [50]. 


\section{Analysis of DNase-Seq and ChIP-Seq data, and genome-wide identification of super-enhancers}

Publicly available data were retrieved from the Gene Expression Omnibus (GEO). ENCODE SK-NMC DNase-Seq (GSM736570) [51] were analyzed in the Nebula environment [52] using Model-based Analysis of ChIP-Seq v1.4.2 (MACS) [53] and converted to *.wig format for display in the UCSC Genome Browser [54]. Preprocessed ChIP-Seq data from Riggi et al. [55] (GSE61944) were converted to *.wig format with the UCSC's bigWigToWig conversion tool.

The following samples were used in this study:

ENCODE_SKNMC_hg19_DNAseHS_rep2

GSM1517546 SKNMC.shGFP96.FLI1

GSM1517555 SKNMC.shFLI196.FLI1

GSM1517547 SKNMC.shGFP96.H3K27ac

GSM1517556 SKNMC.shFLI196.H3K27ac

GSM1517569 A673.shGFP48.FLI1

GSM1517572 A673.shFLI148.FLI1

GSM1517571 A673.shGFP96.H3.k27ac

GSM1517574 A673.shFLI196.H3K27ac

ChIP-seq data of the histone modification H3K27ac in A673 and SK-N-MC Ewing sarcoma cell lines (shGFP96) from a genome-wide chromatin analysis (GSE61944) conducted by Riggi et al. [55] were used for epigenetic analysis of enhancers. The already aligned Sequence Read Archives (*.sra) of both cell lines and the corresponding whole cell extracts were downloaded from GEO. Before peak calling with MACS2 [53], the data were prepared with SAMtools [56]. ChIP peak annotation was done with HOMER [57]. Super-enhancers were identified with ROSE $[28,58]$.

\section{Cell culture, DNA constructs, and reporter assays}

A673/TR/shEF1 Ewing sarcoma cells, which harbor a doxycycline-inducible shRNA against EWSR1FLI1, were described previously [59] and kindly provided by J. Alonso (Madrid, Spain). Unmodified A673 cells were obtained from ATCC. All cells were grown at $37^{\circ} \mathrm{C}$ in $5 \% \mathrm{CO}_{2}$ in a humidified atmosphere in RPMI 1640 medium (Biochrom) containing 10\% Tetracyclinefree FCS (Biochrom), $100 \mathrm{U} / \mathrm{ml}$ penicillin, and $100 \mu \mathrm{g} /$ $\mathrm{ml}$ streptomycin (both Biochrom). Cell line purity was confirmed by short tandem repeat profiling (latest profiling $15^{\text {th }}$ December 2015), and cells were checked routinely for the absence of mycoplasma by PCR. Human GGAAmicrosatellites close to the ATP1A1, BCL11B, or GLG1 gene were cloned from the A673 Ewing sarcoma cell line into the pGL3-luc vector (Promega) upstream of the SV40 minimal promoter. -Primer sequences were as follows:

forward

5'-CTAGCCCGGGCTCGAGAGCAA

CACAAGGACTCAATTAC-3' and reverse
5'-GATCGCAGATCTCGAGCTACTATGATGCAAA

GCTGAGTG-3' for the ATP1A1 associated GGAAmicrosatellite;

forward

5'-CTAGCCCGGGCTCGAG

GCCGTCTCTCTGTTCCTTAT-3' and reverse

5'-GATCGCAGATCTCGAGAATCTCTGCTCCT

TCATCCC-3' for the BCL11B associated GGAAmicrosatellite; and

forward

5'-CTAGCCCGGGCTCGAGGCTACTATAGCCAA

ATGCAAAGAAGAA-3' and reverse

5'-GATCGCAGATCTCGAG TGCACTGGGTTATA-

CAGAAAGAGTTC-3' for the GLG1 associated GGAAmicrosatellite.

For the reporter assays, $3 \times 10^{5} \mathrm{~A} 673 / \mathrm{TR} / \mathrm{shEF} 1$ cells per well of a six-well plate were seeded in $2.5 \mathrm{ml}$ medium and transfected with pGL3-luc vectors and Renilla pGL3-Rluc (ratio, 100:1) using Lipofectamine LTX and Plus Reagent (Invitrogen). After $4 \mathrm{~h}$ transfection media were replaced by media with or without doxycycline (1 $\mu \mathrm{g} / \mathrm{ml})$. Cells were lysed after $72 \mathrm{~h}$ and assayed with a dual luciferase assay system (Berthold). Firefly luciferase activity was normalized to Renilla luciferase activity.

\section{RNA extraction, reverse transcription, and quantitative real-time PCR (qRT-PCR)}

RNA was extracted with the Nucleospin II kit (Macherey-Nagel) and reverse-transcribed using the High-Capacity cDNA Reverse Transcription Kit (Applied Biosystems). qRT-PCRs were performed using SYBR green (Applied Biosystems). Oligonucleotides were purchased from MWG Eurofins Genomics. Reactions were run on a Bio-Rad CFX Connect instrument and analyzed using Bio-Rad CFX Manager 3.1 software. Primer sequences for EWSR1-FLI1 and RPLP0 were reported previously [25].

\section{Construction of TMAs and IHC}

A total of 174 archival formalin-fixed and paraffinembedded (FFPE) primary tissue samples with reviewed histological diagnosis were obtained from the participating institutions and collected at LMU Munich's Institute of Pathology. Representative FFPE tumor blocks were also selected for TMA construction at LMU Munich's Institute of Pathology. A detailed description of the TMA is given in Table 1.

All Ewing sarcoma FFPE samples showed cytogenetic evidence for a translocation of the EWSRI gene as determined by fluorescence in situ hybridization (FISH) and were reviewed by a reference pathologist. For this study, Ewing-like sarcomas were defined as smallround-cell sarcomas being either positive for CIC-DUX4 
(8 cases) or BCOR-CCNB3 (2 cases) or unclassified (7 cases) after extensive reference pathologist work-up. Each TMA slide contained three cores (each $1 \mathrm{~mm}$ in diameter) from every sample as well as internal controls.

For IHC, $4 \mu \mathrm{m}$ sections were cut, and antigen retrieval was performed with microwave treatment with $750 \mathrm{~W}$ at pH7.5 TRIS buffer $(2 \times 15 \mathrm{~min})$ using the antigen retrieval AR kit (DCS, HK057-5KE) for GLG1 or the Target Retrieval Solution (Dako, S1699) for BCL11B and ATP1A1. Blockage of endogenous peroxidase was performed using $7.5 \%$ aqueous $\mathrm{H}_{2} \mathrm{O}_{2}$ solution at room temperature and blocking serum from the corresponding kits for $20 \mathrm{~min}$.

Slides were then incubated for $60 \mathrm{~min}$ with the primary antibodies anti-ATP1A1 (1:330 dilution, Proteintech, 14418-1-AP) [60], anti-BCL11B (1:1,000 dilution, Abcam, ab70453) or anti-GLG1 (1:250 dilution, Sigma, HPA010815) [61]. Then slides were incubated with a secondary anti-rabbit IgG antibody (ImmPress Reagent Kit, Peroxidase-conjugated) followed by target detection using AECplus chromogen for 10 min (Dako, K3461).

For IHC of CD99, 4- $\mu$ m sections were cut and incubated for 32 min with an anti-CD99 antibody (1:40 dilurion, Dako, 12E7) using the Roche UltraView detection kit.

\section{Evaluation of immunoreactivity and automated cut-off finding}

Semi-quantitative evaluation of marker immunostaining was carried out by three independent observers (MCB, MD, MFO) analogous to scoring of hormone receptor IRS ranging from 0-12 according to Remmele and Stegner [31], which is routinely used in surgical pathology to quantify hormone receptor expression in mammary carcinoma.

The percentage of cells with marker expression was scored and classified in five grades (grade $0=0-19 \%$, grade $1=20-39 \%$, grade $2=40-59 \%$, grade $3=60-79 \%$ and grade $4=80-100 \%$ ) after examination of 10 highpower fields $(40 \times)$ of at least one section per sample. In addition, the intensity of marker immunoreactivity was determined $($ grade $0=$ none, grade $1=$ low, grade $2=$ moderate and grade $3=$ strong). The product of these two grades defined the final IRS. Sensitivity and specificity of each marker for Ewing sarcoma were calculated with an in-house generated VBA (Visual Basic for Applications) script implemented in Microsoft Excel (Microsoft). The script computed sensitivity and specificity for all possible combinations of markers and within these combinations, for all possible cut-offs for every marker. The best marker and cut-off combination was chosen based on the following criteria: high specificity (defined as $>95 \%$ ), high sensitivity, and discriminability between positive (IRS higher than the cut-off) and negative samples.

\section{Survival analysis}

Microarray data of 166 primary Ewing sarcoma tumors (GSE63157 [62], GSE34620 [21], GSE12102 [63], and GSE17618 [64]), which had well-curated clinical annotations available, were downloaded from the GEO. The data were generated on Affymetrix HGU133Plus2.0 or Affymetrix HuEx-1.0-st microarray chips and normalized separately by RMA using custom brainarray CDF files (v20). Batch effects were removed using ComBat $[65,66]$. Samples were stratified into two groups based on their median intra-tumoral gene expression levels. Significance levels were calculated with a Mantel-Haenszel test. $P$ values $<0.05$ were considered statistically significant.

\section{Abbreviations}

CDF-chip description file; DSRCT-desmoplastic small-round-cell tumor; GEO-gene expression omnibus; IRS-immunoreactivity score; PCA-principal component analysis; RMA-robust multi-array average; VBAvisual basic for applications; ChIP-Seq-chromatin immunoprecipitation followed by high-throughput sequencing; ER-expression ratio; FGF-fibroblast growth factor; GSEA-gene-set enrichment analysis; IHCimmunohistochemistry; MACS-Model-based Analysis of ChIP-Seq; qRT-PCR-quantitative real-time polymerase chain reaction; TMA-tissue microarray.

\section{Author contributions}

MCB, MFO, MD, and TGPG conceived the study, wrote this paper, and drafted the figures and tables. MCB, JSG, MFO, and TGPG performed bioinformatic and statistical analyses. MMK, NA, ANA, ÖÖ, DB, EdA, UD, WH, and TK provided FFPE samples. MCB, MD, and MFO scored the TMAs. MMLK, RAR, SO, and JL helped in experimental procedures. TK provided laboratory infra-structure. AM, RAR, and GS cloned the GGAAmicrosatellites and performed reporter assays. All authors read and approved the final manuscript.

\section{ACKNOWLEDGMENTS}

We would like to thank Mrs. Andrea Sendelhofert, Mrs. Anja Heier, and Mrs. Mona Melz for excellent technical assistance. The authors would like to thank all the donors and the Hospital Universitario Virgen del Rocío-Instituto de Biomedicina de Sevilla Biobank (Andalusian Public Health System Biobank and ISCIIIBiobank Platform PT13/0010/0056) for the human specimens used in this study. 


\section{CONFLICTS OF INTEREST}

The authors declare no conflict of interest.

\section{FUNDING}

This work was supported by the Kind-PhilippFoundation (to J.M., M.C.B., M.F.O., M.D., A.M, and G.S.), the 'Deutsche Stiftung für Junge Erwachsene mit Krebs' (to M.D.), the German National Academic Foundation (to M.C.B. and M.M.L.K.), the 'Verein zur Förderung von Wissenschaft und Forschung an der Medizinischen Fakultät der LMU München' (WiFoMed; to T.G.P.G.), the Daimler and Benz Foundation in cooperation with the Reinhard Frank Foundation (to T.G.P.G.), the Friedrich-Baur-Stiftung (to T.G.P.G.) by LMU Munich's Institutional Strategy LMUexcellent within the framework of the German Excellence Initiative (to T.G.P.G.), the 'Mehr LEBEN für krebskranke Kinder - Bettina-Bräu-Stiftung' (to T.G.P.G.), the Fritz-Thyssen Foundation (FTF-40.15.0.030MN, to T.G.P.G. and G.S.), the Wilhelm-Sander-Foundation (2016.167.1 to T.G.P.G.), and the German Cancer Aid (DKH-111886 and DKH70112257 to T.G.P.G.; DKH-108128 to U.D.), EU FP7 and TRANSCAN EraNet - PROVABES [01KT1310], EU-FP7 EEC [602856-2] to U.D.

\section{Editorial note}

This paper has been accepted based in part on peerreview conducted by another journal and the authors' response and revisions as well as expedited peer-review in Oncotarget.

\section{REFERENCES}

1. Delattre O, Zucman J, Melot T, Garau XS, Zucker JM, Lenoir GM, Ambros PF, Sheer D, Turc-Carel C, Triche TJ, Aurias A, Thomas G. The Ewing family of tumors-a subgroup of small-round-cell tumors defined by specific chimeric transcripts. N Engl J Med. 1994; 331:294-99. https://doi.org/10.1056/NEJM199408043310503

2. Machado I, Noguera R, Pellin A, Lopez-Guerrero JA, Piqueras M, Navarro S, Llombart-Bosch A. Molecular diagnosis of Ewing sarcoma family of tumors: a comparative analysis of 560 cases with FISH and RTPCR. Diagn Mol Pathol. 2009; 18:189-99. https://doi. org/10.1097/PDM.0b013e3181a06f66

3. Doyle LA. Sarcoma classification: an update based on the 2013 World Health Organization Classification of Tumors of Soft Tissue and Bone. Cancer. 2014; 120:1763-74. https://doi.org/10.1002/cncr.28657

4. Fletcher CD. The evolving classification of soft tissue tumours - an update based on the new 2013 WHO classification. Histopathology. 2014; 64:2-11. https://doi. org/10.1111/his.12267

5. Parham DM. Modern Diagnosis of Small Cell Malignancies of Children. Surg Pathol Clin. 2010; 3:515-51. https://doi. org/10.1016/j.path.2010.06.002

6. Antonescu C. Round cell sarcomas beyond Ewing: emerging entities. Histopathology. 2014; 64:26-37. https:// doi.org/10.1111/his.12281

7. Pierron G, Tirode F, Lucchesi C, Reynaud S, Ballet S, Cohen-Gogo S, Perrin V, Coindre JM, Delattre O. A new subtype of bone sarcoma defined by BCOR-CCNB3 gene fusion. Nat Genet. 2012; 44:461-66. https://doi. org/10.1038/ng.1107

8. Italiano A, Sung YS, Zhang L, Singer S, Maki RG, Coindre JM, Antonescu CR. High prevalence of CIC fusion with double-homeobox (DUX4) transcription factors in EWSR1negative undifferentiated small blue round cell sarcomas. Genes Chromosomes Cancer. 2012; 51:207-18. https:/doi. org/10.1002/gcc.20945

9. Szuhai K, Ijszenga M, de Jong D, Karseladze A, Tanke HJ, Hogendoorn PC. The NFATc2 gene is involved in a novel cloned translocation in a Ewing sarcoma variant that couples its function in immunology to oncology. Clin Cancer Res. 2009; 15:2259-68. https://doi.org/10.1158/1078-0432. CCR-08-2184

10. Kawamura-Saito M, Yamazaki Y, Kaneko K, Kawaguchi N, Kanda H, Mukai H, Gotoh T, Motoi T, Fukayama M, Aburatani H, Takizawa T, Nakamura T. Fusion between CIC and DUX4 up-regulates PEA3 family genes in Ewinglike sarcomas with $\mathrm{t}(4 ; 19)(\mathrm{q} 35 ; \mathrm{q} 13)$ translocation. Hum Mol Genet. 2006; 15:2125-37. https://doi.org/10.1093/hmg/ dd1136

11. Machado I, Navarro L, Pellin A, Navarro S, Agaimy A, Tardío JC, Karseladze A, Petrov S, Scotlandi K, Picci P, Llombart-Bosch A. Defining Ewing and Ewing-like small round cell tumors (SRCT): the need for molecular techniques in their categorization and differential diagnosis. A study of 200 cases. Ann Diagn Pathol. 2016; 22:25-32. https://doi.org/10.1016/j.anndiagpath.2016.03.002

12. Cohen-Gogo S, Cellier C, Coindre JM, Mosseri V, Pierron G, Guillemet C, Italiano A, Brugières L, Orbach D, Laurence V, Delattre O, Michon J. Ewing-like sarcomas with BCOR-CCNB3 fusion transcript: a clinical, radiological and pathological retrospective study from the Société Française des Cancers de L'Enfant. Pediatr Blood Cancer. 2014; 61:2191-98. https://doi.org/10.1002/ pbc. 25210

13. Machado I, Navarro S, Llombart-Bosch A. Ewing sarcoma and the new emerging Ewing-like sarcomas: (CIC and BCOR-rearranged-sarcomas). A systematic review. Histol Histopathol. 2016; 31:1169-81. https://doi.org/10.14670/ HH-11-792

14. Papp G, Mihály D, Sápi Z. Unusual Signal Patterns of Break-apart FISH Probes Used in the Diagnosis of Soft Tissue Sarcomas. Pathol Oncol Res. 2017; 23:863-871. https://doi.org/10.1007/s12253-017-0200-z 
15. Peter M, Gilbert E, Delattre O. A multiplex real-time pcr assay for the detection of gene fusions observed in solid tumors. Lab Invest. 2001; 81:905-12. https://doi. org/10.1038/labinvest.3780299

16. Olsen SH, Thomas DG, Lucas DR. Cluster analysis of immunohistochemical profiles in synovial sarcoma, malignant peripheral nerve sheath tumor, and Ewing sarcoma. Mod Pathol. 2006; 19:659-68. https://doi. org/10.1038/modpathol.3800569

17. Lee SP, Park S, Park J, Hong J, Ko YH. Clinicopathologic characteristics of CD99-positive diffuse large B-cell lymphoma. Acta Haematol. 2011; 125:167-74. https://doi. org/10.1159/000322551

18. Fisher C. Synovial sarcoma. Ann Diagn Pathol. 1998; 2:401-21. https://doi.org/10.1016/S1092-9134(98)80042-7

19. Rossi S, Orvieto E, Furlanetto A, Laurino L, Ninfo V, Dei Tos AP. Utility of the immunohistochemical detection of FLI-1 expression in round cell and vascular neoplasm using a monoclonal antibody. Mod Pathol. 2004; 17:547-52. https://doi.org/10.1038/modpathol.3800065

20. Hung YP, Fletcher CD, Hornick JL. Evaluation of NKX22 expression in round cell sarcomas and other tumors with EWSR1 rearrangement: imperfect specificity for Ewing sarcoma. Mod Pathol. 2016; 29:370-80. https://doi. org/10.1038/modpathol.2016.31

21. Postel-Vinay S, Véron AS, Tirode F, Pierron G, Reynaud S, Kovar H, Oberlin O, Lapouble E, Ballet S, Lucchesi C, Kontny U, González-Neira A, Picci P, et al. Common variants near TARDBP and EGR2 are associated with susceptibility to Ewing sarcoma. Nat Genet. 2012; 44:32327. https://doi.org/10.1038/ng.1085

22. Hu-Lieskovan S, Zhang J, Wu L, Shimada H, Schofield DE, Triche TJ. EWS-FLI1 fusion protein up-regulates critical genes in neural crest development and is responsible for the observed phenotype of Ewing's family of tumors. Cancer Res. 2005; 65:4633-44. https://doi.org/10.1158/0008-5472. CAN-04-2857

23. Wiles ET, Lui-Sargent B, Bell R, Lessnick SL. BCL11B is up-regulated by EWS/FLI and contributes to the transformed phenotype in Ewing sarcoma. PLoS One. 2013; 8:e59369. https://doi.org/10.1371/journal.pone.0059369

24. Gangwal K, Sankar S, Hollenhorst PC, Kinsey M, Haroldsen SC, Shah AA, Boucher KM, Watkins WS, Jorde LB, Graves BJ, Lessnick SL. Microsatellites as EWS/FLI response elements in Ewing's sarcoma. Proc Natl Acad Sci USA. 2008; 105:10149-54. https://doi.org/10.1073/ pnas.0801073105

25. Grünewald TG, Bernard V, Gilardi-Hebenstreit P, Raynal V, Surdez D, Aynaud MM, Mirabeau O, Cidre-Aranaz F, Tirode F, Zaidi S, Perot G, Jonker AH, Lucchesi C, et al. Chimeric EWSR1-FLI1 regulates the Ewing sarcoma susceptibility gene EGR2 via a GGAA microsatellite. Nat Genet. 2015; 47:1073-78. https://doi.org/10.1038/ng.3363

26. Patel M, Simon JM, Iglesia MD, Wu SB, McFadden
AW, Lieb JD, Davis IJ. Tumor-specific retargeting of an oncogenic transcription factor chimera results in dysregulation of chromatin and transcription. Genome Res. 2012; 22:259-70. https://doi.org/10.1101/gr.125666.111

27. Tomazou EM, Sheffield NC, Schmidl C, Schuster M, Schönegger A, Datlinger P, Kubicek S, Bock C, Kovar H. Epigenome mapping reveals distinct modes of gene regulation and widespread enhancer reprogramming by the oncogenic fusion protein EWS-FLI1. Cell Reports. 2015; 10:1082-95. https://doi.org/10.1016/j.celrep.2015.01.042

28. Whyte WA, Orlando DA, Hnisz D, Abraham BJ, Lin CY, Kagey MH, Rahl PB, Lee TI, Young RA. Master transcription factors and mediator establish super-enhancers at key cell identity genes. Cell. 2013; 153:307-19. https:// doi.org/10.1016/j.cell.2013.03.035

29. Hnisz D, Abraham BJ, Lee TI, Lau A, Saint-André V, Sigova AA, Hoke HA, Young RA. Super-enhancers in the control of cell identity and disease. Cell. 2013; 155:934-47. https://doi.org/10.1016/j.cell.2013.09.053

30. Wei GH, Badis G, Berger MF, Kivioja T, Palin K, Enge M, Bonke M, Jolma A, Varjosalo M, Gehrke AR, Yan J, Talukder S, Turunen M, et al. Genome-wide analysis of ETS-family DNA-binding in vitro and in vivo. EMBO J. 2010; 29:2147-60. https://doi.org/10.1038/emboj.2010.106

31. Remmele W, Stegner HE. [Recommendation for uniform definition of an immunoreactive score (IRS) for immunohistochemical estrogen receptor detection (ER-ICA) in breast cancer tissue]. [Article in German]. Pathologe. 1987; 8:138-40.

32. Specht K, Sung YS, Zhang L, Richter GH, Fletcher CD, Antonescu CR. Distinct transcriptional signature and immunoprofile of CIC-DUX4 fusion-positive round cell tumors compared to EWSR1-rearranged Ewing sarcomas: further evidence toward distinct pathologic entities. Genes Chromosomes Cancer. 2014; 53:622-33. https://doi. org/10.1002/gcc.22172

33. Charville GW, Wang WL, Ingram DR, Roy A, Thomas D, Patel RM, Hornick JL, van de Rijn M, Lazar AJ. EWSR1 fusion proteins mediate PAX7 expression in Ewing sarcoma. Mod Pathol. 2017; 30:1312-1320. https://doi. org/10.1038/modpathol.2017.49

34. Romeo S, Dei Tos AP. Soft tissue tumors associated with EWSR1 translocation. Virchows Arch. 2010; 456:219-34. https://doi.org/10.1007/s00428-009-0854-3

35. Surdez D, Benetkiewicz M, Perrin V, Han ZY, Pierron G, Ballet S, Lamoureux F, Rédini F, Decouvelaere AV, Daudigeos-Dubus E, Geoerger B, de Pinieux G, Delattre $O$, Tirode F. Targeting the EWSR1-FLI1 oncogeneinduced protein kinase PKC- $\beta$ abolishes ewing sarcoma growth. Cancer Res. 2012; 72:4494-503. https://doi. org/10.1158/0008-5472.CAN-12-0371

36. Shibuya R, Matsuyama A, Nakamoto M, Shiba E, Kasai T, Hisaoka M. The combination of CD99 and NKX2.2, a transcriptional target of EWSR1-FLI1, is highly specific 
for the diagnosis of Ewing sarcoma. Virchows Arch. 2014; 465:599-605. https://doi.org/10.1007/s00428-014-1627-1

37. Kawaguchi S, Wada T, Tsukahara T, Ida K, Torigoe T, Sato $\mathrm{N}$, Yamashita T. A quest for therapeutic antigens in bone and soft tissue sarcoma. J Transl Med. 2005; 3:31. https:// doi.org/10.1186/1479-5876-3-31

38. Iwahori K, Suzuki H, Kishi Y, Fujii Y, Uehara R, Okamoto N, Kobayashi M, Hirashima T, Kawase I, Naka T. Serum HE4 as a diagnostic and prognostic marker for lung cancer. Tumour Biol. 2012; 33:1141-49. https://doi.org/10.1007/ s13277-012-0356-9

39. Papale M, Vocino G, Lucarelli G, Rutigliano M, Gigante M, Rocchetti MT, Pesce F, Sanguedolce F, Bufo P, Battaglia M, Stallone G, Grandaliano G, Carrieri G, et al. Urinary RKIP/p-RKIP is a potential diagnostic and prognostic marker of clear cell renal cell carcinoma. Oncotarget. 2017; 8:40412-24. https://doi.org/10.18632/oncotarget.16341

40. Zacherl S, La Venuta G, Müller HM, Wegehingel S, Dimou E, Sehr P, Lewis JD, Erfle H, Pepperkok R, Nickel W. A direct role for ATP1A1 in unconventional secretion of fibroblast growth factor 2. J Biol Chem. 2015; 290:3654 65. https://doi.org/10.1074/jbc.M114.590067

41. Cidre-Aranaz F, Grünewald TG, Surdez D, García-García L, Carlos Lázaro J, Kirchner T, González-González L, Sastre A, García-Miguel P, López-Pérez SE, Monzón S, Delattre O, Alonso J. EWS-FLI1-mediated suppression of the RASantagonist Sprouty 1 (SPRY1) confers aggressiveness to Ewing sarcoma. Oncogene. 2017; 36:766-76. https://doi. org/10.1038/onc.2016.244

42. Zuber ME, Zhou Z, Burrus LW, Olwin BB. Cysteine-rich FGF receptor regulates intracellular FGF-1 and FGF2 levels. J Cell Physiol. 1997; 170: 217-27. https://doi. org/10.1002/(SICI)1097-4652(199703)170:3<217::AIDJCP1>3.0.CO;2-R

43. Girnita L, Girnita A, Wang M, Meis-Kindblom JM, Kindblom LG, Larsson O. A link between basic fibroblast growth factor (bFGF) and EWS/FLI-1 in Ewing's sarcoma cells. Oncogene. 2000; 19:4298-301. https://doi. org/10.1038/sj.onc. 1203755

44. Agelopoulos K, Richter GH, Schmidt E, Dirksen U, von Heyking K, Moser B, Klein HU, Kontny U, Dugas M, Poos K, Korsching E, Buch T, Weckesser M, et al. Deep Sequencing in Conjunction with Expression and Functional Analyses Reveals Activation of FGFR1 in Ewing Sarcoma. Clin Cancer Res. 2015; 21:4935-46. https://doi. org/10.1158/1078-0432.CCR-14-2744

45. Dai M, Wang P, Boyd AD, Kostov G, Athey B, Jones EG, Bunney WE, Myers RM, Speed TP, Akil H, Watson SJ, Meng F. Evolving gene/transcript definitions significantly alter the interpretation of GeneChip data. Nucleic Acids Res. 2005; 33:e175. https://doi.org/10.1093/nar/gni179

46. R Development Core Team. R: A language and environment for statistical computing. Vienna, Austria; Available from: http://www.R-project.org
47. Gordon DJ, Motwani M, Pellman D. Modeling the initiation of Ewing sarcoma tumorigenesis in differentiating human embryonic stem cells. Oncogene. 2016; 35:3092-102. https://doi.org/10.1038/onc.2015.368

48. Kauer M, Ban J, Kofler R, Walker B, Davis S, Meltzer P, Kovar H. A molecular function map of Ewing's sarcoma. PLoS One. 2009; 4:e5415. https://doi.org/10.1371/journal. pone. 0005415

49. Bilke S, Schwentner R, Yang F, Kauer M, Jug G, Walker RL, Davis S, Zhu YJ, Pineda M, Meltzer PS, Kovar H. Oncogenic ETS fusions deregulate E2F3 target genes in Ewing sarcoma and prostate cancer. Genome Res. 2013; 23:1797-809. https://doi.org/10.1101/gr.151340.112

50. Subramanian A, Tamayo P, Mootha VK, Mukherjee S, Ebert BL, Gillette MA, Paulovich A, Pomeroy SL, Golub TR, Lander ES, Mesirov JP. Gene set enrichment analysis: a knowledge-based approach for interpreting genomewide expression profiles. Proc Natl Acad Sci USA. 2005; 102:15545-50. https://doi.org/10.1073/pnas.0506580102

51. Thurman RE, Rynes E, Humbert R, Vierstra J, Maurano MT, Haugen E, Sheffield NC, Stergachis AB, Wang H, Vernot B, Garg K, John S, Sandstrom R, et al. The accessible chromatin landscape of the human genome. Nature. 2012; 489:75-82. https://doi.org/10.1038/ nature 11232

52. Boeva V, Lermine A, Barette C, Guillouf C, Barillot E. Nebula-a web-server for advanced ChIP-seq data analysis. Bioinformatics. 2012; 28:2517-19. https://doi.org/10.1093/ bioinformatics/bts463

53. Zhang Y, Liu T, Meyer CA, Eeckhoute J, Johnson DS, Bernstein BE, Nusbaum C, Myers RM, Brown M, Li W, Liu XS. Model-based analysis of ChIP-Seq (MACS). Genome Biol. 2008; 9:R137. https://doi.org/10.1186/gb2008-9-9-r137

54. Meyer LR, Zweig AS, Hinrichs AS, Karolchik D, Kuhn RM, Wong M, Sloan CA, Rosenbloom KR, Roe G, Rhead B, Raney BJ, Pohl A, Malladi VS, et al. The UCSC Genome Browser database: extensions and updates 2013. Nucleic Acids Res. 2013; 41:D64-69. https://doi.org/10.1093/nar/ gks 1048

55. Riggi N, Knoechel B, Gillespie SM, Rheinbay E, Boulay G, Suvà ML, Rossetti NE, Boonseng WE, Oksuz $\mathrm{O}$, Cook EB, Formey A, Patel A, Gymrek M, et al. EWS-FLI1 utilizes divergent chromatin remodeling mechanisms to directly activate or repress enhancer elements in Ewing sarcoma. Cancer Cell. 2014; 26:668-81. https://doi.org/10.1016/j. ccell.2014.10.004

56. Li H, Handsaker B, Wysoker A, Fennell T, Ruan J, Homer N, Marth G, Abecasis G, Durbin R, and 1000 Genome Project Data Processing Subgroup. The Sequence Alignment/Map format and SAMtools. Bioinformatics. 2009; 25:2078-79. https://doi.org/10.1093/bioinformatics/ btp 352

57. Heinz S, Benner C, Spann N, Bertolino E, Lin YC, Laslo P, Cheng JX, Murre C, Singh H, Glass CK. Simple 
combinations of lineage-determining transcription factors prime cis-regulatory elements required for macrophage and B cell identities. Mol Cell. 2010; 38:576-89. https://doi. org/10.1016/j.molcel.2010.05.004

58. Lovén J, Hoke HA, Lin CY, Lau A, Orlando DA, Vakoc CR, Bradner JE, Lee TI, Young RA. Selective inhibition of tumor oncogenes by disruption of super-enhancers. Cell. 2013; 153:320-34. https://doi.org/10.1016/j. cell.2013.03.036

59. Carrillo J, García-Aragoncillo E, Azorín D, Agra N, Sastre A, González-Mediero I, García-Miguel P, Pestaña A, Gallego S, Segura D, Alonso J. Cholecystokinin downregulation by RNA interference impairs Ewing tumor growth. Clin Cancer Res. 2007; 13:2429-40. https://doi. org/10.1158/1078-0432.CCR-06-1762

60. Yan X, Xun M, Dou X, Wu L, Zhang F, Zheng J. Activation of Na+-K+-ATPase with DRm217 attenuates oxidative stress-induced myocardial cell injury via closing $\mathrm{Na}+-\mathrm{K}+$ ATPase/Src/Ros amplifier. Apoptosis. 2017; 22:531-43. https://doi.org/10.1007/s10495-016-1342-2

61. Morisaki T, Yashiro M, Kakehashi A, Inagaki A, Kinoshita H, Fukuoka T, Kasashima H, Masuda G, Sakurai K, Kubo N, Muguruma K, Ohira M, Wanibuchi H, Hirakawa K. Comparative proteomics analysis of gastric cancer stem cells. PLoS One. 2014; 9:e110736. https://doi.org/10.1371/ journal.pone.0110736

62. Volchenboum SL, Andrade J, Huang L, Barkauskas DA, Krailo M, Womer RB, Ranft A, Potratz J, Dirksen U, Triche TJ, Lawlor ER. Gene Expression Profiling of Ewing Sarcoma Tumors Reveals the Prognostic Importance of Tumor-Stromal Interactions: A Report from the Children's Oncology Group. J Pathol Clin Res. 2015; 1:83-94. https:// doi.org/10.1002/cjp2.9
63. Scotlandi K, Remondini D, Castellani G, Manara MC, Nardi F, Cantiani L, Francesconi M, Mercuri M, Caccuri AM, Serra M, Knuutila S, Picci P. Overcoming resistance to conventional drugs in Ewing sarcoma and identification of molecular predictors of outcome. J Clin Oncol. 2009; 27:2209-16. https://doi.org/10.1200/JCO.2008.19.2542

64. Savola S, Klami A, Myllykangas S, Manara C, Scotlandi K, Picci P, Knuutila S, Vakkila J. High Expression of Complement Component 5 (C5) at Tumor Site Associates with Superior Survival in Ewing's Sarcoma Family of Tumour Patients. ISRN Oncol. 2011; 2011:168712. https:// doi.org/10.5402/2011/168712

65. Stein CK, Qu P, Epstein J, Buros A, Rosenthal A, Crowley J, Morgan G, Barlogie B. Removing batch effects from purified plasma cell gene expression microarrays with modified ComBat. BMC Bioinformatics. 2015; 16:63. https://doi.org/10.1186/s12859-015-0478-3

66. Johnson WE, Li C, Rabinovic A. Adjusting batch effects in microarray expression data using empirical Bayes methods. Biostatistics. 2007; 8:118-27. https://doi.org/10.1093/ biostatistics/kxj037 